\title{
Authentication of herbal products to attract global markets
}

\author{
Rekha R. Warrier \\ Division of Plant Biotechnology and Cytogenetics, Institute of Forest Genetics and Tree Breeding, Forest Campus, R.S. Puram, P.B No. 1061, \\ Coimbatore, Tamil Nadu, India

\section{Article Info} \\ Article history : Received 1 October 2021, Revised 17 November 2021, Accepted 19 November 2021, Published Online 30 December 2021
}

\section{Introduction}

Plants as a source of food and medicine have been in existence since humankind evolved. Health and illness have always co-existed. The healing properties of plants would have been identified through human instinct. Based on further observations and effectiveness in recovery, this knowledge might have been supplemented over time. Ancient civilisations reveal that the use of plants for therapeutic purposes extends back to the earliest part of recorded history. Free exchange of knowledge also took place between the different systems enriching them.

Traditional healthcare has been in practice in India for centuries. The Ayurveda, Unani, Siddha and Unani forms have existed since 4500 BC. Ancient texts like Rig veda and Atharva veda (2000 BC) mention plants as medicine. Today, the concept of Traditional Systems of Medicine, which uses plants to treat illness, is of global importance. Charaka Samhita (300 BC) and Sushrutasamhita (1300 BC), Sanskrit treatises on medicine, refer to more than 700 herbs. The Indian Systems of Medicine (ISM) use about 8,000 plants. Currently, about 950 species are used by the Indian herbal industry. Many of them are traded in volumes exceeding 100 MT annually (Goraya and Ved, 2017).

Since the 1800 s, there has been continued interest in medicinal plant research. The advent of the Europeans in India kindled interest in the scientific scrutiny of traditional practices. Scientific validation of therapeutic effects of plants gained prominence. Sarpagandha (Rauvolfia serpentina), a medicinal plant described by Susruta, an ancient Indian surgeon, was the first plant studied for pharmacological actions. Later, its clinical efficacy as an antihypertensive agent was proven. This discovery provided tremendous impetus to medicinal plant research globally. Since then, more than 3000 plants have been screened for various biological activities through a multipronged approach.

\section{Need for continued research on medicinal plants}

Despite rapid technological advancements, only a fraction of plant species has been examined critically. Even though, there have been outstanding achievements in synthesising several vital drugs for many dreadful diseases, a complete cure is still not available for many disorders. It would be worthwhile to explore the vast flora available in India to find a remedy, at least for some of them.

In India, almost 80 per cent of the population rely on traditional medicines. The sales turnover of indigenous medicine is about one

Copyright (C) 2021 Ukaaz Publications. All rights reserved.

Email: ukaaz@yahoo.com; Website: www.ukaazpublications.com and half times that of modern medicines. With the WHO recognising the traditional systems of medicine, there is a renewed interest in native medicines. Extensive data are available on many plants' metabolism, phytochemical, and pharmacological activities. The WHO also stressed the need to investigate medicinal plants to understand better their properties, safety and efficacy. Remarkable achievements have been made in instrumental technology in phytochemical, cell and tissue culture research. Biological activity assessment techniques have been refined. This has also led to increased demands of medicinal plants for pharmaceuticals, phytochemicals, nutraceuticals, cosmetics and other products. As a result, though rich in floristic wealth, many plant species are disappearing at an alarming rate in India. This has also paved the way for adulteration/substitution.

\section{Efficacy and safety of herbal medicines}

One of the major reasons herbal medicines are not accepted in Western countries is the lack of accurate identification of genuine raw material. Widespread adulteration/substitution in the crude drug market, leads to poor quality of medicinal formulations. Hence, safety and efficacy of herbal medicines is becoming a matter of concern.

\subsection{Adulteration}

Today, many herbs are replaced with substandard commercial varieties, inferior or artificially manufactured commodities. Due to physical similarity, it becomes difficult to differentiate for the untrained eye. These adulterants may neither have any therapeutic value nor the desired chemical component. In some instances, chemically synthesised compounds are mixed. The latter is practised to enhance the concentration of active principles. Common adulterant examples are the roots of turmeric and pepper.

\subsection{Substitution}

Over-exploitation, unsustainable harvesting, habitat degradation, illegal trade and decimation of several RET medicinal plants encourage substitution. It involves replacing or intentionally adding a foreign substance to increase product weight or potency or decrease its cost. Another reason is when different species have a common name like Ashoka (Saraca asoca/Polyalthia longifolia). They have distinct morphological and taxonomic characters along with different phytochemical constituents. Another classic example is Brahmi which refers to both Bacopa monnieri and Centella asiatica. Added to this, a single plant that has multiple vernacular names adds to further confusion. 


\subsection{Provenance variations in active principles}

Geography plays a role in variation in the active compoundsaltitude, climatic conditions, growing species outside their ecological niches, cultivation in stressed sites, alter bioactive compounds. Though, biosynthesis of secondary metabolites is largely genetically controlled, they are also, to a large extent, influenced by biotic or abiotic environmental factors. Variations in the azadirachtin content in neem distributed throughout the country is a good example. Seasonal variations, and different stages of vegetative growth also influence the variations in secondary metabolites.

\section{Establishing the authenticity of medicinal plants}

Authentication of the plant material right from its identification in the field to its developmental stages, followed by appropriate harvest, storage and finally culminating into the final product is a the need of the hour. This ensures the standard quality of herbal medicine, ensuring its safety and efficacy. Different methods have been used for the authentication of different medicinal plants. Most of the regulatory guidelines (WHO, 2018) suggest macro/microscopic evaluation and chemical profiling of botanical materials for quality control and standardisation. Morphological and anatomical study, chemical analysis and metabolite profiling using TLC, HPLC, MS, gas chromatography and spectrometry help identify adulterants, differentiate herbal medicines, confirm proprietary products' stability, etc. The genetic makeup is unique for each species and is not affected by age, physiological conditions, and environmental factors. Therefore, identifying species from a herbal concoction or plant can be done using DNA-based markers.

Genetic markers that have proved their utility in different plant sciences are presently being used in the pharmacognostic characterisation of herbal medicines. Various DNA-based markers, both dominant (RAPD, ISSR, AFLP) and co-dominant (RFLP, SSR, SCAR), are employed for plant species discrimination along with taxonomy, physiology, embryology and genetic variation (Warrier et al., 2019). Genome analysis based on molecular markers has generated a vast amount of information and a number of data bases are being generated to preserve and popularise it (Warrier et al., 2020).

\section{DNA barcodes: An efficient tool for authentication of herbal medicines}

DNA barcoding makes use of short, standardised regions of the genome called barcodes which are unique to different species. These short strands have been identified as appropriate for testing herbal plants, powders, and to a certain extent, unidentified species. DNA barcoding uses universal markers in conserved genomic regions (ideal = large variation between species, small variation within species). Barcoding projects have already generated reference barcodes for many species. DNA metabarcoding, an advancement over the former, includes high-throughput sequencing (HTS). This technique enables identification of multiple taxa from complex mixtures as observed with herbal mixtures or powders. However, due to the method's high sensitivity, there is a strong probability of false positives. False-positive cases are detection of foreign particles such as pollen from another species deposited on the species of interest, presence of parasitic plants, etc. False negatives are bound to happen due to the loss or degradation of DNA during the product processing stages when samples are subjected to high temperatures or adulterated using synthetic drugs.

Increasing interest in herbal medicines and a lull in the supply of species from the wild trigger a demand-motivated intentional adulteration. Based on the WHO, there is a $10-30 \%$ globally estimated presence of counterfeit medicinal products (WHO, 2018). Molecular diagnostic tools provide an efficient quality assurance and supply chain verification of herbal medicines. However, these methods are not yet widespread in the regulatory regime of quality control. There are several studies to prove its usefulness for product authentication and pharmacovigilance. Many of the CITES-listed species are detected using these methods.

Currently, most herbal preparations do not meet the legal requirements of quality control and assurance. It is time we addressed this issue of authenticating constituents in herbal medicines using advanced technologies. Analytical chemistry methods could be adopted to detect contaminants and toxins as a preliminary step. Eventually, DNA metabarcoding could be used to confirm the authentic species' presence, complementary to the standard methods. This would enable the accurate identification of plant species and prove an excellent tool to authenticate complex herbal products. However, standardization of protocols would be necessary for the different products before deployment in regulatory frameworks.

Research on phytomedicines would continue to grow, given the increasing demand for herbal medicines. This also requires wider dissemination for regular updating of advancements in this field. The Annals of Phytomedicine: An International Journal provides a dedicated platform presenting the latest topics with critical analysis. This journal has collated excellent information about herbals in the light of the pandemic, providing scope for interested researchers to pursue unexplored areas. The journal acts as an excellent vehicle to deliver information on herbal products, including advanced technologies in a time-bound manner.

\section{Conflict of interest}

The author declares no conflicts of interest relevant to this article.

\section{References}

Goraya, G.S. and Ved , D. K. (2017). Medicinal Plants in India : An assessment of their demand and supply, NMPB and ICFRE.

Warrier, R.R.; Geeta Joshi and Arunkumar, A.N. (2019). DNA fingerprinting in industrially important medicinal trees. Ann. Phytomed., 8(1):19-35.

Warrier, R.R.; Geetha, S.; Sivakumar, V.; Singh, B.G. and Anandalakshmi, R., (2020). Threatened tree species of the Western Ghats: Status, diversity and conservation. In conservation and utilization of threatened medicinal plants, pp:429-460. Springer, Cham.

World Health Organization (2018). A study on the public health and socioeconomic impact of substandard and falsified medical products. Geneva: WHO, pp:67. 


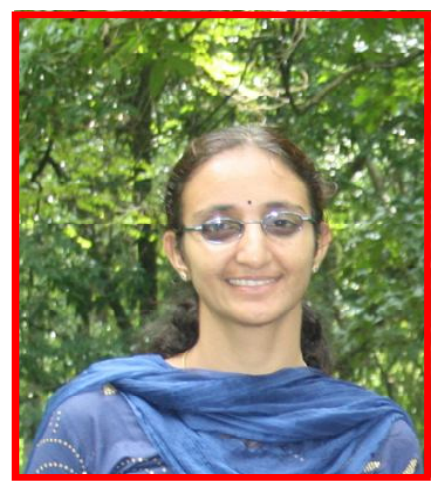

Rekha R. Warrier

Division of Plant Biotechnology and Cytogenetics, Institute of Forest Genetics and Tree Breeding, Forest Campus, R.S. Puram, P.B No. 1061, Coimbatore, Tamil Nadu, India

\section{Biography}

Dr. Rekha R. Warrier, works at the Plant Biotechnology Division, Institute of Forest Genetics and Tree Breeding (IFGTB), Coimbatore. She is currently serving as the head of the Plant Tissue Culture group. Some of her major activities include-tissue culture facility for commercial production of plants and in vitro production of secondary metabolites through transformation; genetic improvement of medicinal trees; stress physiology, early prediction of orchard gains through "Breeding without Breeding"; and participation in extension and training programs. Associated with various forestry agencies, she had opportunities to work in moist deciduous and evergreen ecosystems in the tropics. Dr. Rekha has been a Principal Investigator in 20 research projects and has 70 research papers and 15 books/ chapters to her credit. She manages the National DUS (Distinctness, Uniformity and Stability) centre for Meliadubia at IFGTB. Presently, she is the Assistant National Country Co-ordinator of the Asia Pacific Forest Genetic Resources Programme (APFORGEN) and Co-Chair of the Board. She is also a member of Western Ghats Plant Group of the SSC of the IUCN and Liason to the Central Secretariat of the India Chapter of ISTF. 